\title{
Study on the Mechanisms of Gases Emissions in Mould Powders Applied in the Continuous Casting of Steel
}

\author{
M. Valentini* ${ }^{*}$ E. Brandaleze
}

High Temperature Physicochemistry Group -DEYTEMA-Facultad Regional San Nicolás, Universidad Tecnológica Nacional, Colón 332 (B2900LWH) San Nicolás, Argentina

Commercial continuous casting mould powders are complex oxides systems that also present different contents of $\mathrm{C}$ and fluorite $\left(\mathrm{CaF}_{2}\right)$. The last compound is added to develop the adequate physical properties and heat extraction characteristics required during steel industrial production. However, at process conditions mould powders provokes complex gases emissions. These risks lead researchers to develop new mould powder compositions that meet not only the requirements for metallurgical functions but also to avoid problems of fluorinated gases emissions that means a risk to operator's health and lead to corrosion problems of industrial equipment. In this sense, it is important to understand fluorinated gases formation mechanisms at process conditions and also to clarify the fluorine functions in order to evaluate possible replacement compounds alternatives. Undoubtedly, currently the development of fluorine free mould powders, marks a worldwide trend that accompanies the development of clean technologies. In this paper two mould powders, with and without fluorite $\left(\mathrm{CaF}_{2}\right)$, are characterized considering physical properties behaviour at high temperature such as viscosity, fluidity and surface tension, crystallization tendency, gases emissions generation, applying different experimental tests and thermodynamic simulation using Fact Sage 8.0, in order to identify gases emissions mechanisms.

Keywords: Mould powders, fluorine, physical properties, gases emissions, clean technologies.

Copyright $\odot 2020$ The Author(s): This is an open-access article distributed under the terms of the Creative Commons Attribution 4.0 International License (CC BY-NC 4.0) which permits unrestricted use, distribution, and reproduction in any medium for non-commercial use provided the original author and source are credited.

\section{INTRODUCTION}

It is known that the industry undergoes permanent controls on the environment in the world. The technological advancement has enabled the development of methods of planning and equipment for pollution control [1]. The main pollutants of the steel industry are $\mathrm{SO}_{2}, \mathrm{SO}_{3}, \mathrm{CO}, \mathrm{NO}, \mathrm{SH}$, fluorine, fluorides, hydrochloric acid, sulfuric acid, zinc fumes, red fumes, acid vapors, smells [2]. The atmospheric pollutants drive to damage on humans, plants, buildings, monuments, objects and ecosystems.

Looking at the particular aspect of gases emissions, over the past three decades many efforts have been made to reduce emissions of gases and particulates by approximately 50\%. The current environmental demands impulse the steel industry to make a new technological leap. This motivates the generation of research and development projects, aimed at reducing the level of pollutant emissions. In the steel continuous casting process mould powders play important roles: the molten steel protection from re-oxidation, inclusions absorption, provide thermal insulation, lubrication and heat transfer control (between the mold and the steel shell). All the mentioned functions are determined by the chemical composition and physical properties of mould flux such as viscosity, fluidity, surface tension and crystallization tendency [3]. Mould powders are mainly formed by a mix of oxides: $\mathrm{SiO}_{2}, \mathrm{CaO}, \mathrm{Al}_{2} \mathrm{O}_{3}, \mathrm{Na}_{2} \mathrm{O}$, etc., combined with $\mathrm{CaF}_{2}$ and $\mathrm{C}$. As was mentioned in previous papers $[4,5]$, mould powders contain fluorite $\left(\mathrm{CaF}_{2}\right)$ additions in their chemical composition (up to $\sim 10 \%$ ), with the aim of guaranteeing physical properties and crystallization tendency. As result of industrial operation conditions, gaseous fluorides are originated (mainly $\mathrm{SiF}_{4}, \mathrm{NaF}, \mathrm{KF}$ and others) that could cause air pollution or reactions with the environment to form hydrofluoric acid (HF), etc [6-8]. In this paper the thermal behavior during heating and cooling of two synthetic slags (with and without fluorine content) are evaluated by thermal analysis tests (DTA TG) to establish the reactions or transformations occurred in the material as a function of temperature. The results are correlated with thermodynamic simulation carried out applying FactSage 8.0. In addition, the physical properties (viscosity, surface tension and fluidity) are 
determined by experimental tests and theoretical estimations. The melting behavior of both materials have been studied by hot stage microscopy (HSM). Also the crystallization tendency was determined by quenched tests at $\mathrm{T}=1300^{\circ} \mathrm{C}$ and a microstructural study, applying optical and scanning electron microscopy. The information was correlated with results of $\mathrm{X}$ ray diffraction and of the thermodynamic study in order to evaluate the crystalline phases composition and characteristics. Fluorine acts as a silicate network breaker and control the viscosity of mould powder. In addition constitutes the main component of the crystalline phase generated during cooling, cuspidine (3 $\mathrm{CaO} .2 \mathrm{SiO}_{2} \cdot \mathrm{CaF}_{2}$ ) [3]. In order to avoid gases emissions, different researchers have studied the effect of alternatives compounds for fluorite replacement: $\mathrm{B}_{2} \mathrm{O}_{3}$, $\mathrm{Na}_{2} \mathrm{CO}_{3}, \mathrm{Li}_{2} \mathrm{O}, \mathrm{TiO}_{2}, \mathrm{Fe}_{2} \mathrm{O}_{3}, \mathrm{ZnO}$, etc. Many studies considered $\mathrm{B}_{2} \mathrm{O}_{3}$ impact on mould powder viscosity and it was found that this property decreases with the increase of $\mathrm{B}_{2} \mathrm{O}_{3}$ content $[3,5]$. The research of the development of F-free mould powders for the casting of medium carbon steels present difficulties in the control of crystallization. For this reason, in this study a deep knowledge on the thermodynamic evolution of the phases generated in the systems during cooling is relevant to be considered. The thermodynamic simulation carried out applying Fact Sage 8.0 also constitute a good tool to predict solid and liquid phases present at process temperatures conditions [9-11].

\section{EXPERIMENTAL PROCEDURE}

The chemical composition of the mould powder was determined by different instrumental techniques. The melting behaviour and the contact angle were determined by hot stage microscopy (HSM). On the base of the contact angle values the surface tension was estimated by a theoretical model developed to this purpose. The viscosity variation in relation with temperatures between $1200^{\circ} \mathrm{C}$ to $1550^{\circ} \mathrm{C}$ was estimated by FactSage 8.0 .
In order to evaluate the thermal behaviour of both samples thermal analysis tests (DTA TG) were performed by a SHIMADZU DTG-60/60H instrument considering heating (up to $1300^{\circ} \mathrm{C}$ ) and cooling conditions. The tests were performed at $10{ }^{\circ} \mathrm{C} / \mathrm{min}$. The results obtained were correlated with phases (gas, liquid and solid states) predicted by thermodynamic simulation carried out by FactSage 8.0. These simulation was carried out using de Equilib module and databases: GTOX 7.3, FToxid 8.0, FTsalt 8.0, FactPS 8.0, including information of gas ions. The temperature conditions considered are $300^{\circ} \mathrm{C}$ to $1500^{\circ} \mathrm{C}$ and $\mathrm{p}=1$ at.

In addition, samples of both mould fluxes were melted and quenched from $\mathrm{T}=1300^{\circ} \mathrm{C}$ in order to evaluate the crystallization tendency. The crystalline phases present in both samples were identified integrating $\mathrm{X}$ ray diffraction, a structural study and also results obtained by the simulation.

For the structural study, samples were included in epoxy resin and prepared for microscopy observations by polishing with $\mathrm{SiC}$ (400 to 1000) and diamond paste up to $1 \square \mathrm{m}$. The structure of the samples was observed by optical microscopy applying a light microscope OLYMPUS GX 51 with image analyzer Material Plus. The study was completed by scanning electron microscopy (SEM + EDS).

\section{RESULTS AND DISCUSSIONS}

In the case of medium carbon steels casting, mould powders commonly present $\mathrm{CaF}_{2}$ between 4 to $10 \%$ in their composition [12]. The mould powder A (with fluorite content) selected for this study is a commercial product used for medium carbon steel casting and present $10.4 \%$ wt. of $\mathrm{CaF}_{2}$ and the mould powder $\mathrm{B}$ (without fluorite) was designed for this study with $\mathrm{B}_{2} \mathrm{O}_{3}\left(6 \%\right.$ wt.) and $\mathrm{Li}_{2} \mathrm{O}(4 \%$ wt.), in replacement of fluorite. In Table-1, the main oxides content and the basicity index (BI) of both materials are detailed.

Table-1: Chemical composition of mould powder samples in wt\%

\begin{tabular}{|l|l|l|l|l|l|l|l|l|}
\hline Samples & $\mathrm{SiO}_{2}$ & $\mathrm{CaO}$ & $\mathrm{MgO}$ & $\mathrm{Al}_{2} \mathrm{O}_{3}$ & $\mathrm{Na}_{2} \mathrm{O}+\mathrm{K}_{2} \mathrm{O}$ & $\mathrm{B}_{2} \mathrm{O}_{3}$ & $\mathrm{Li}_{2} \mathrm{O}$ & $\mathrm{BI}$ \\
\hline $\mathrm{A}$ & 36.2 & 30.8 & 2.1 & 5.1 & 13.4 & - & - & 0.85 \\
\hline $\mathrm{B}$ & 34.3 & 30.1 & 2.0 & 4.7 & 19.0 & 5.9 & 3.9 & 0.87 \\
\hline
\end{tabular}

The critical temperatures and contact angles of both samples were determined by hot stage microscopy (HSM), Table-2. 
Table-2: Melting behaviour of the samples determined by HSM

\begin{tabular}{|c|c|c|c|c|}
\hline Sample & $\mathrm{T}_{\mathrm{i}}$ & $\mathrm{T}_{\mathrm{s}}$ & $T_{h}$ & $T_{f}$ \\
\hline \multicolumn{5}{|l|}{ A } \\
\hline & $20^{\circ} \mathrm{C}$ & $1077^{\circ} \mathrm{C}$ & $1094^{\circ} \mathrm{C}$ & $1_{1130}^{\circ} \mathrm{C}$ \\
\hline$\square$ & $90^{\circ}$ & $77^{\circ}$ & $51^{\circ}$ & $26^{\circ}$ \\
\hline \multicolumn{5}{|l|}{ B } \\
\hline & $2^{\circ} \mathrm{C}$ & $921^{\circ} \mathrm{C}$ & $966^{\circ} \mathrm{C}$ & $1010^{\circ} \mathrm{C}$ \\
\hline$\square$ & $90^{\circ}$ & $80^{\circ}$ & $52^{\circ}$ & $26^{\circ}$ \\
\hline
\end{tabular}

It is relevant to note that samples present quite similar melting behaviour and contact angle values $(\square \square$, however sample B start to melt at lower temperatures than mould powder A. This behaviour of B mould powder could guaranty an improvement of the liquid pool generation in the mold. This constitutes an important requirement in order to achieve a good performance in the continuous casting operation [12, 13]. The comparison of the viscosity behaviour associated with temperature (for both samples) was predicted by FactSage 8.0 applying the viscosity module, see Figure-1. Both samples present a similar viscosity behaviour. At continuous casting process condition $\left(\sim 1500^{\circ} \mathrm{C}\right)$, the difference of the viscosity values between $\mathrm{A}$ and $\mathrm{B}$ mould powders is $\square \square \sim 0.5$ Poise. The viscosities and melting results are in agreement with D. Larson et al in [14], that comments that the higher viscosity of the mould powder the slower melting rate. Surface tension values ( $\square$ ) in $\mathrm{mN} / \mathrm{m}$ at each critical temperature $\left(T_{s}, T_{h}\right.$ and $\left.T_{f}\right)$ for the sample $B$ are lower than for the sample A, see Figure-2.

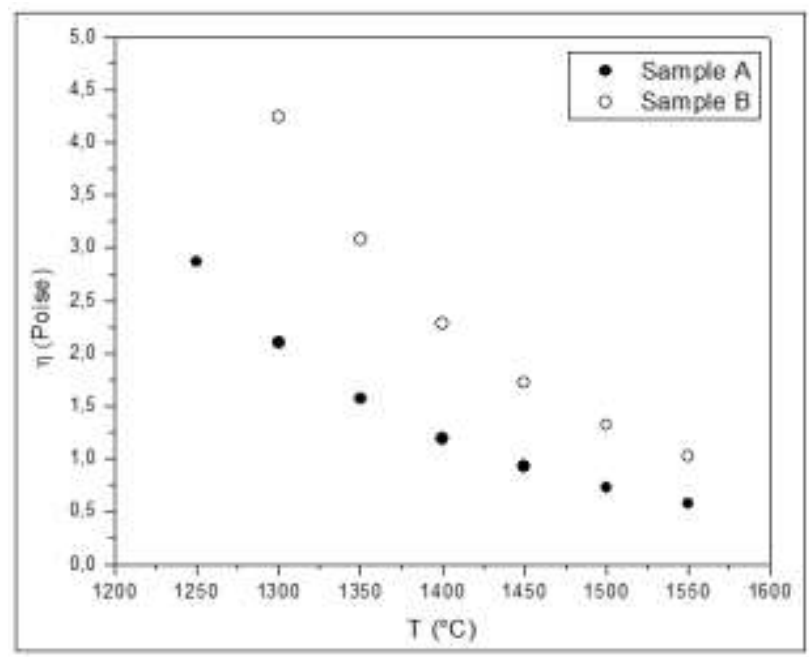

Fig-1: Viscosity behaviour of the mould powders A and B predicted by FactSage 8.0

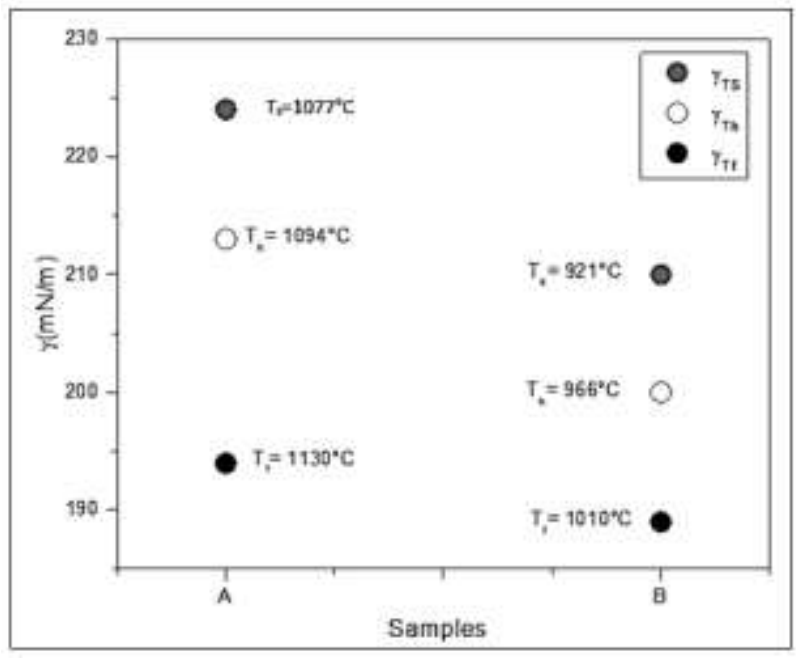

Fig-2: Surface tension values $(\square)$ of the mould powders $A$ and $B$ at each critical temperature

Both physical properties are very important in mould powders performance during casting operation and also in the inclusions absorption capacity [15]. $\mathrm{CaF}_{2}$, $\mathrm{Na}_{2} \mathrm{O}$ constitute network modifiers in mold fluxes which drastically alter the network structures of the mould powder and in consequence cause their physical properties variations. $\mathrm{B}_{2} \mathrm{O}_{3}$ is also a surface-active constituent that affects the physical properties including the surface tension in the liquid phase [16]. The surface tension of mould powders constitutes one of the most important parameters to control the interfacial phenomena associated with steel cleanness during the continuous-casting process. In agreement with [17], the inclusions are eliminated from steel when they are pick up by the mould powder. The lower surface tension of the sample B is considered favorable for inclusions capture from the steel. From this point of view, this mould powder constitute an opportunity of improvement for the steel quality.

The thermal behaviour of both mould powders (A and B) are evaluated by DTA TG tests. The results were correlated with the information obtained by the thermodynamic simulation carried out applying Fact Sage 8.0. DTA TG curves allows to observe that critical 
temperature values $\left(\mathrm{T}_{\mathrm{s}}, \mathrm{T}_{\mathrm{h}}\right.$, and $\mathrm{T}_{\mathrm{f}}$ ) obtained by HSM (Table-2), are consistent with the melting behaviour determined by DTA tests and the thermodynamic study in both cases. In addition, DTA curves shows the melting point $\mathrm{T}_{\mathrm{m}}$ of the samples (A and $\mathrm{B}$ ), that are not possible to be measured by HSM test.

Sample A thermal behaviour, is observed in the DTA and TG curves, see figures 3 and 4. DTA curve indicates that at $\mathrm{T}_{1 \mathrm{~L}}=750^{\circ} \mathrm{C}$ (in agreement with thermodynamic simulation results) the mould powder start to generate the first liquid phase which contains $\mathrm{F}$ in the chemical composition. At temperatures $\mathrm{T} \sim 950^{\circ} \mathrm{C}$ two liquid phases with $\mathrm{F}$ content are predicted in the system, justifying the change of morphology of HSM sample at $\mathrm{T}_{\mathrm{s}}$ (softening critical temperature). DTA curve in coincidence with HSM results indicate the melting behaviour occur at the temperatures range between $\mathrm{T}_{\mathrm{i}}=1077^{\circ} \mathrm{C}$ and $\mathrm{T}_{\mathrm{f}}=1130^{\circ} \mathrm{C}$ and the melting temperature of the sample $\mathrm{A}$ is $\mathrm{T}_{\mathrm{m}}=1224^{\circ} \mathrm{C}$.

The thermogravimetric curve (TG) provides information about the mass variations occurred in the material as a function of temperature, Figure-4. It is observed that there are two major stages of mass loss in sample A, during heating. The first stage occurs below $750{ }^{\circ} \mathrm{C}$, where a variation $\Delta \mathrm{m}_{1}=-13.3 \%$ is observed and would mainly correspond to the removal of humidity and crystallization water of the compounds present in the mould powder. This result is corroborated also by the thermodynamic simulation. The second stage, $\Delta \mathrm{m}_{2}=$ $-8.6 \%$, observed at temperatures higher than $750{ }^{\circ} \mathrm{C}$, is associated with carbonates decomposition in the material and the emission of $\mathrm{NaF}$ gas at temperatures $\mathrm{T}>1150^{\circ} \mathrm{C}$. At higher temperatures, $\mathrm{T}>1400^{\circ} \mathrm{C} \mathrm{NaF}$ and $\mathrm{KF}$ are generated. Both gases emissions are predicted by Fact Sage. At higher temperatures a negligible quantity of $(\mathrm{NaF})_{2}$ is determined. The total mass loss during heating of the sample $\mathrm{A}$ is $21.9 \%$.

In the case of sample B, the thermal behaviour is shown in figures 5 and 6 . DTA curve indicates that at $\mathrm{T}_{1 \mathrm{~L}}>750^{\circ} \mathrm{C}$ (in agreement with thermodynamic simulation results) the mould powder start to generate liquid phases. The thermodynamic simulation predicts two liquid phases in the system: $\mathrm{LiBO}_{2}$ and $\mathrm{B}$. This information is consistent with the critical temperatures $\left(\mathrm{T}_{\mathrm{s}}, \mathrm{T}_{\mathrm{h}}, \mathrm{T}_{\mathrm{f}}\right)$ determined by HSM. The melting temperature of sample $\mathrm{B}$ is $\mathrm{T}_{\mathrm{m}}=1244^{\circ} \mathrm{C}$. DTA curve also shows two exothermic reactions at $\mathrm{T}<750^{\circ} \mathrm{C}$. The heat produced in both reactions improve the mould powder melting behaviour and results in the lower critical temperatures. In addition, TG curve of sample B allows to note that the mould powder present a considerable lower mass loss respect the sample A ( $\square \mathrm{m}=-5.15 \%)$. At temperatures higher than $1350^{\circ} \mathrm{C}$ the simulation predicts a negligible gases formation, mainly constituted by $\mathrm{Na}, \mathrm{NaBO}_{2}$ and $\mathrm{LiBO}_{2}$ and $\mathrm{Na}_{2}$.

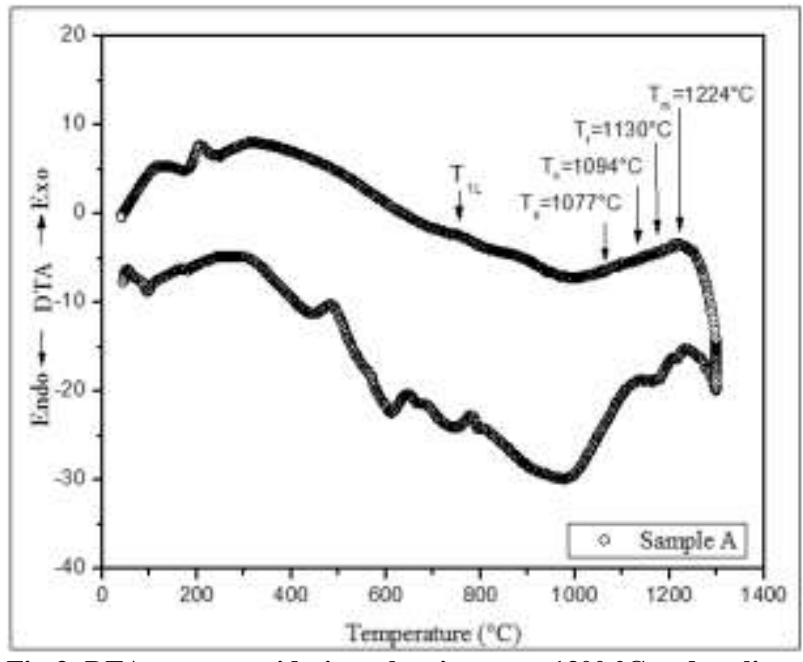

Fig-3: DTA curve considering a heating up to $1300{ }^{\circ} \mathrm{C}$ and cooling of the sample A

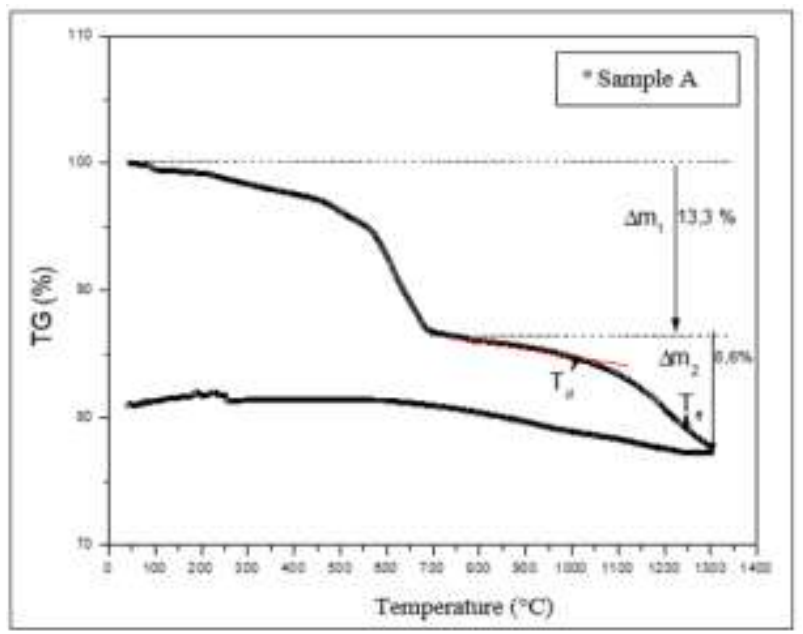

Fig-4: TG curve of sample A considering a heating up to $1300{ }^{\circ} \mathrm{C}$

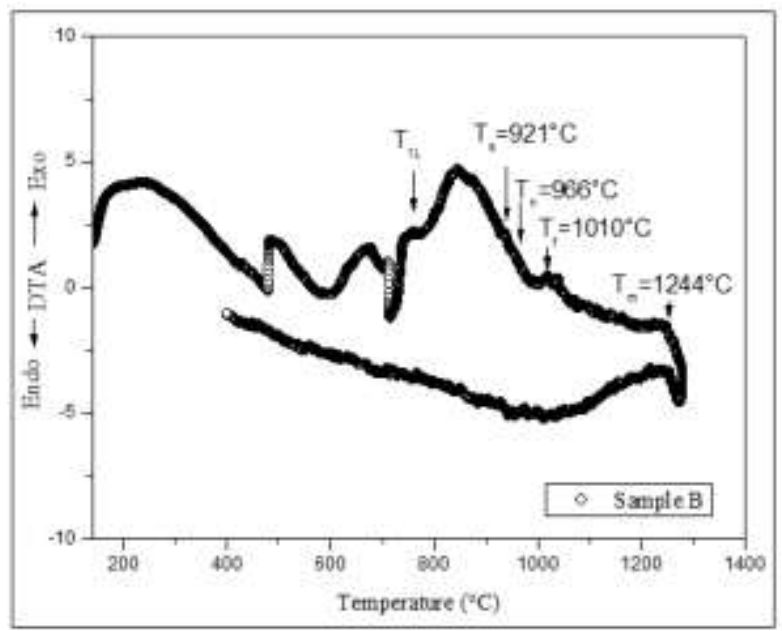

Fig-5: DTA curve considering a heating up to $1300^{\circ} \mathrm{C}$ and cooling of the sample $B$ 


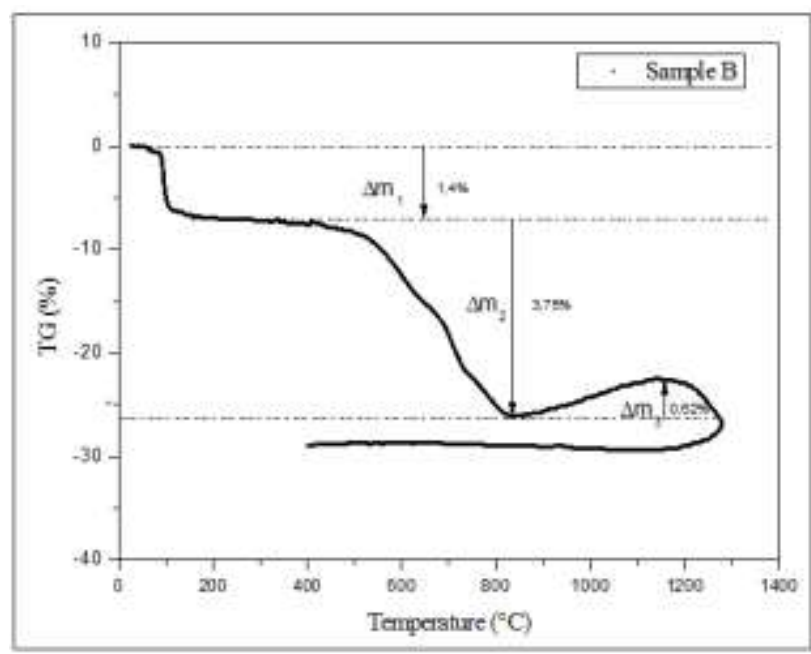

Fig-6: TG curve of sample $B$ considering a heating up to $1300{ }^{\circ} \mathbf{C}$

It is also important to consider that in sample A, $\mathrm{CaF}_{2}$ promotes the melting of the system and in consequence fluorine is present in the liquid phases generated. At temperatures $\mathrm{T} \sim 1150^{\circ} \mathrm{C}$ fluorine reacts in the system to form $\mathrm{NaF}$ gas. At higher temperatures $\left(\sim 1400^{\circ} \mathrm{C}\right) \mathrm{KF}$ gas and negligible quantity of $(\mathrm{NaF})_{2}$ are produced. In Figure 7 the main gases ( $\mathrm{NaF}$ and KF) generated at different temperature conditions (up to the continuous casting operation temperatures $\mathrm{T} \geq 1500^{\circ} \mathrm{C}$ ) are plotted for sample A. This results justifies the gradual loss of mass obtained by TG test.

The results obtained by the thermodynamic simulation indicates that in the continuous casting operation the gas emission predicted for mould powder $\mathrm{A}$ is $\sim 3.10^{-2} \mathrm{~g} / 100 \mathrm{~g}$ contributing to the air pollution along the time de processing. Fluorinated gases along the time could present different types of impacts on human health, industrial infrastructure and environment damage. These results are consistent with the results obtained by Person and Seetharaman [17], since they established based on thermogravimetric tests (TG) that the emission of fluorinated gases occurs in the mould powders at temperatures around $1200{ }^{\circ} \mathrm{C}$.

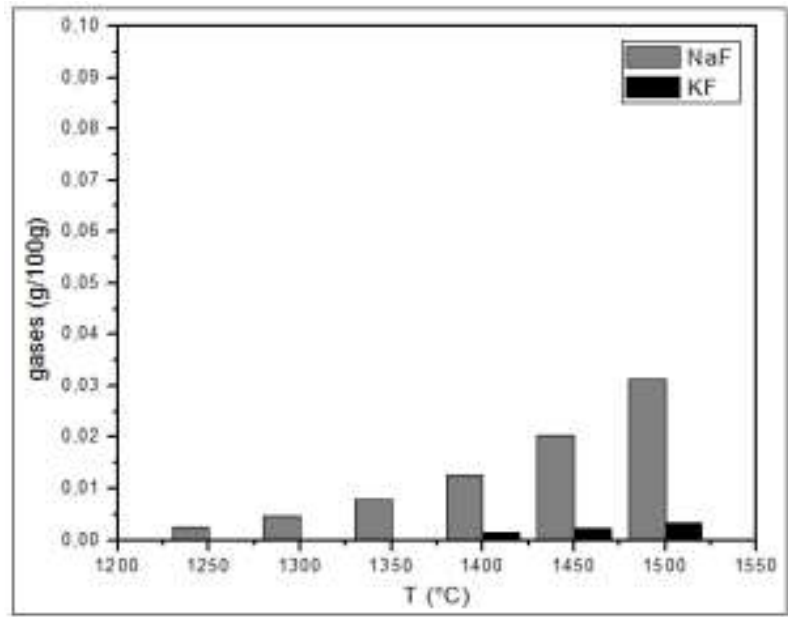

Fig-7: Gases emission evolution with the temperature in sample A (up to $1500{ }^{\circ} \mathrm{C}$ )

On the contrary, sample B generates negligible low quantity of gases emissions, in consequence it could be consider a mould powder with lower risk and also the few gases formed are produced only between $\left(1350^{\circ} \mathrm{C}-1500^{\circ} \mathrm{C}\right)$.

In the sample $\mathrm{A}$, the higher fugacity of $\mathrm{NaF}$ respect to the other gases $\left(\mathrm{KF}\right.$ and $\left.(\mathrm{NaF})_{2}\right)$, explains the greater mass of this gas emitted at temperatures $(\mathrm{T} \geq$ $1250{ }^{\circ} \mathrm{C}$ ) in this material, see Figure 8. In the case of sample $\mathrm{B}$, the fugacity of the $\mathrm{Na}$ gas is considerable higher respect the other gases $\left(\mathrm{NaBO}_{2}\right.$ and $\left.\mathrm{LiBO}_{2}\right)$ at the temperature $\mathrm{T} \geq 1300^{\circ} \mathrm{C}$ (Figure-9). Although gas formation in sample $\mathrm{B}$ is insignificant, it is relevant to consider that $\mathrm{Na}$ which is the main gas formed in these material decrease drastically the fugacity up to $1500^{\circ} \mathrm{C}$. This behaviour allows to consider that $\mathrm{Na}$ present a tendency to remain in liquid or solid phases during the operation conditions.

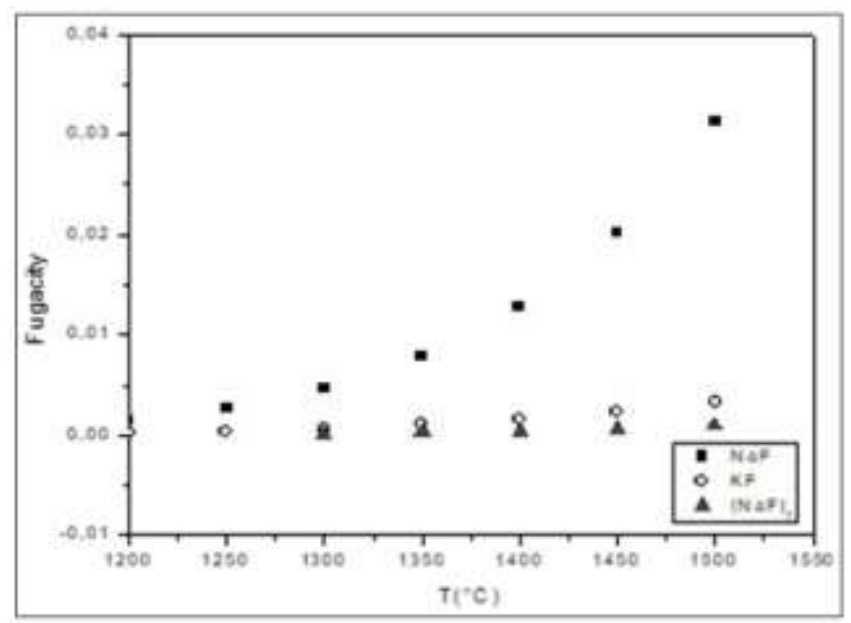

Fig-8: Evolution of gases fugacity in the sample $A$ between $1200^{\circ} \mathrm{C}$ and $1500{ }^{\circ} \mathrm{C}$ 


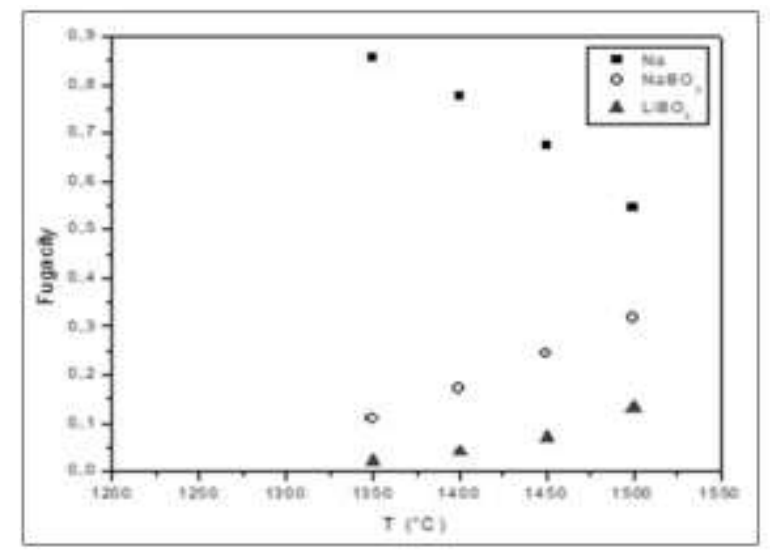

Fig-9: Evolution of gases fugacity in the sample $B$ at temperatures $\mathrm{T} \geq 1350^{\circ} \mathrm{C}$

As it was previously mentioned, $\mathrm{CaF}_{2}$ functions in the mould powder is to control physical properties (such as viscosity ( $\square \square \square$ surface tension ( $\square \square$, etc.) and the crystallization tendency to provide adequate heat extraction in the mould [4]. For this reason, in this paper results of the structure evolution of both samples treated at $1300^{\circ} \mathrm{C}$, were also analyzed. The study was carried out through $\mathrm{X}$ ray diffraction (XRD) tests and microscopy techniques (including optical and scanning electron microscopy with EDS). The diffractograms of both samples are visualized in Figure 10 and 11.

It is known that the crystalline phases contribute to the control of the heat extraction during the solidification of a medium carbon steel [12]. The results show that both samples presents an adequate crystallization at the same temperature. The chemical composition differences promote different crystalline phases types in each case however in similar proportion, that allows to think in a similar heat extraction in the mould. The main crystalline phases developed in each sample are detailed in Table-3.

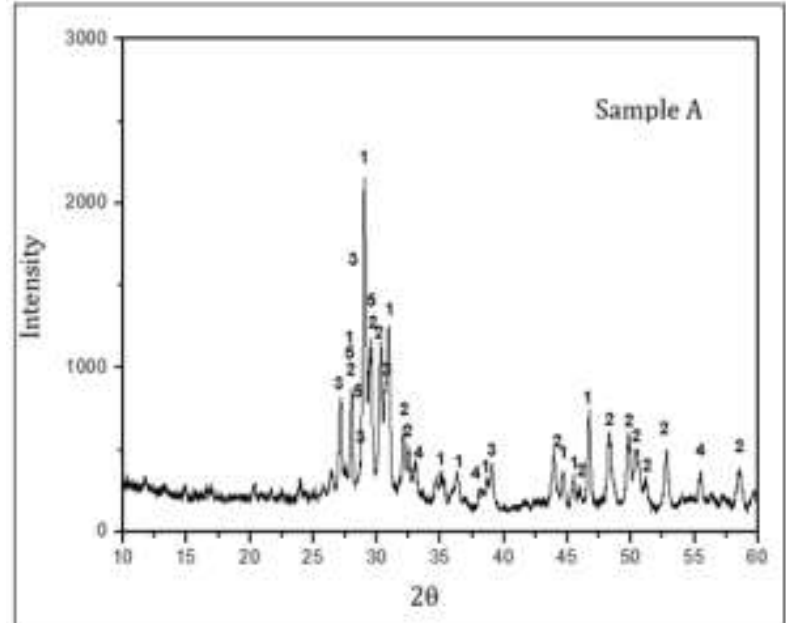

Fig-10: Crystal phases present in the sample $A$ at $1300^{\circ} \mathrm{C}$

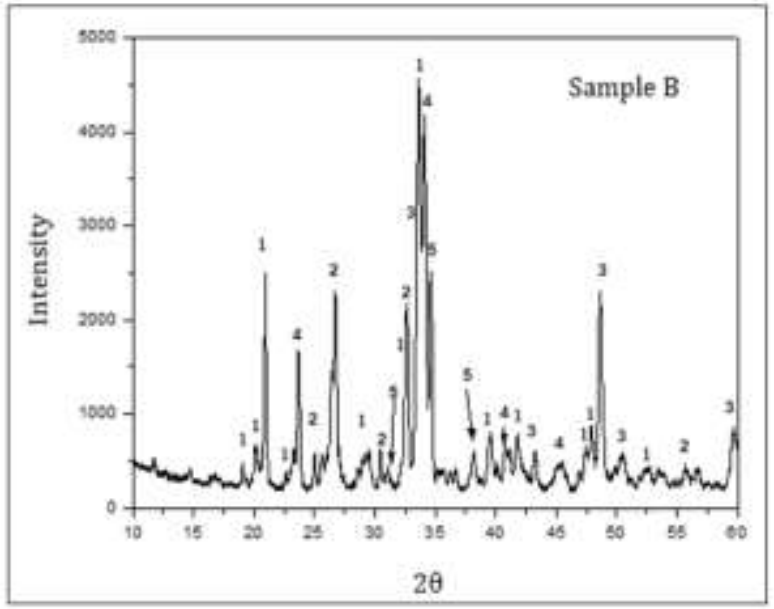

Fig-11: Crystal phases present in the sample $B$ at $1300^{\circ} \mathrm{C}$

Table-3: Crystalline phases determined by $\mathrm{X}$ ray diffraction (XRD).

\begin{tabular}{|l|l|}
\hline Sample A crystalline phases & Sample B crystalline phases \\
\hline 1-Cuspidine $\left(\mathrm{Ca}_{4} \mathrm{~F}_{2} \mathrm{O}_{7} \mathrm{Si}_{2}\right)$ - monoclinic & 1-Combeite $\left(\mathrm{Ca}_{1,5} \mathrm{Na}_{2,9} \mathrm{O}_{9} \mathrm{Si}_{3}\right)$ - trigonal \\
\hline 2-Tetracalcium difluoride disilicate $\left(\mathrm{Ca}_{4} \mathrm{~F}_{2} \mathrm{O}_{7} \mathrm{Si}_{2}\right)$ - monoclinic & 2-Damburite $\left(\mathrm{B}_{2} \mathrm{CaO}_{8} \mathrm{Si}_{2}\right)$ - orthorhombic \\
\hline 3-Nefeline $\left(\mathrm{Al}_{3,79} \mathrm{Ca}_{0,4} \mathrm{~K}_{0,8} \mathrm{Na}_{3} \mathrm{O}_{16} \mathrm{Si}_{4,21}\right)$ - hexagonal & 3-Borato de $\mathrm{Na}\left(\mathrm{NaB}_{2} \mathrm{O}_{4}\right)$ - orthorhombic \\
\hline 4-Villaumite $(\mathrm{NaF})$ - trigonal & 4- $\mathrm{B}_{4} \mathrm{KLi}_{3} \mathrm{O}_{8}$ - trigonal \\
\hline 5- Anorthoclase $\left(\mathrm{Al}_{1} \mathrm{Ca}_{0,1} \mathrm{~K}_{0,27} \mathrm{Na}_{0,63} \mathrm{O}_{8} \mathrm{Si}_{2,9}\right)$ - triclinic & 5- $\mathrm{B}_{4} \mathrm{KLiO}_{7}$ - orthorhombic \\
\hline
\end{tabular}

The thermodynamic simulation results obtained for sample A, are in agreement with the phases determined by XRD and also with the microstructural study. It was possible to determined that the main crystalline phases at $1300^{\circ} \mathrm{C}$ in the sample $\mathrm{A}$ are: cuspidine $\left(\mathrm{CaO} \cdot 2 \mathrm{SiO}_{2} \cdot \mathrm{CaF}_{2}\right)$, nepheline $\left(\mathrm{Al}_{4} \mathrm{Ca}_{0.4} \mathrm{~K}_{0.8} \mathrm{Na}_{2} \mathrm{Si}_{4}\right)$ and villaumite $(\mathrm{NaF})$.

Both phases, cuspidine $\left(\mathrm{CaO} \cdot 2 \mathrm{SiO}_{2} \cdot \mathrm{CaF}_{2}\right)$ and villaumite $(\mathrm{NaF})$ present fluorine in the composition.

In the case of mould powder B the main crystalline phases identified are: combeite $\left(\mathrm{Na}_{2} \mathrm{Ca}_{2} \mathrm{Si}_{3} \mathrm{O}_{9}\right)$, damburite $\left(\mathrm{B}_{2} \mathrm{CaO}_{8} \mathrm{Si}_{2}\right)$ and lower quantities of sodium and lithium borates. Crystal phases compositions shows that $\mathrm{Na}$ are present in two of them: combeite $\left(\mathrm{Na}_{2} \mathrm{Ca}_{2} \mathrm{Si}_{3} \mathrm{O}_{9}\right)$ and sodium borate $\left(\mathrm{NaB}_{2} \mathrm{O}_{4}\right)$.

The structural study carried out by optical microscopy allows to evaluate the crystalline layer's morphology characteristics in both samples (A and B) and to measure the thickness, Figure 12 (a) and (b). In sample B the crystalline layer is thicker $(\sim 140 \square \mathrm{m})$ than of sample $\mathrm{A}(\sim 40 \square \mathrm{m})$. 


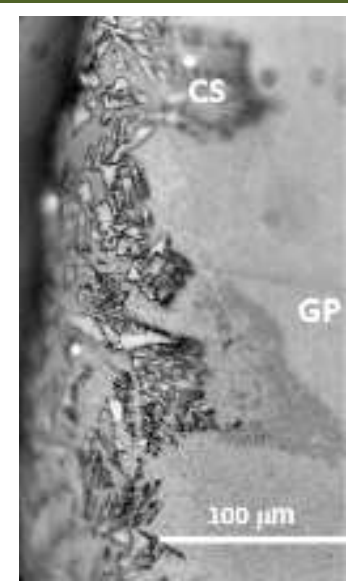

(a) Crystalline layer observed in sample A

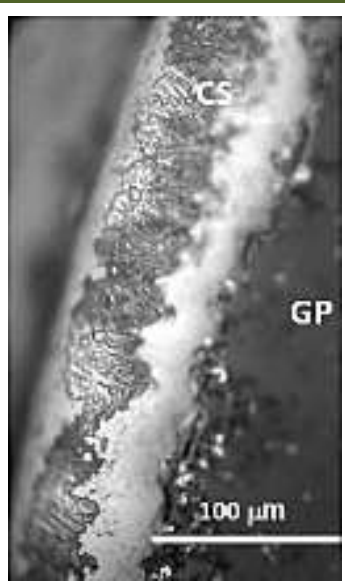

(b) Crystalline layer observed in sample B

Fig-12: Characteristics of the crystalline layer observed in the samples A and B, GP: glass phase and CS: surface crystal layer

The differences in crystalline phases proportions determined by microscopy could explain the slightly higher viscosity behaviour of the mould flux B respect sample A [4]. Both samples are constituted by a glassy phase (GP) combined with a surface crystal layer in the surface (CS). In both cases, the crystal layer's presents dendritic morphology. The crystallization developed in the samples allows to predict an approximate thermal extraction in the mould. It was possible to establish that the dendritic crystals for both samples present a similar morphology. The crystals growth is oriented to the opposite direction respect the heat extraction. Figure-13, shows as an example the cuspidine dendritic crystals growth direction in sample A. The dendritic structural aspects were also observed with high magnification by SEM. In Figure-14 a detail of the dendrite structure of combeite phase (sample B) is presented.

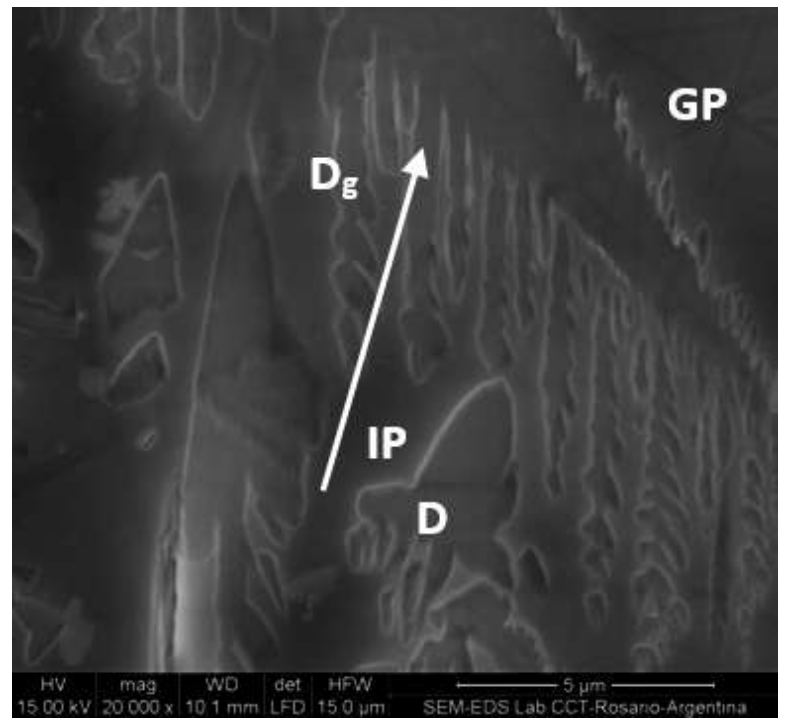

Fig-13: Dendritic growth observed in sample A. GP: glassy phase, IP: interdedritic phase and D: dendritic crystal

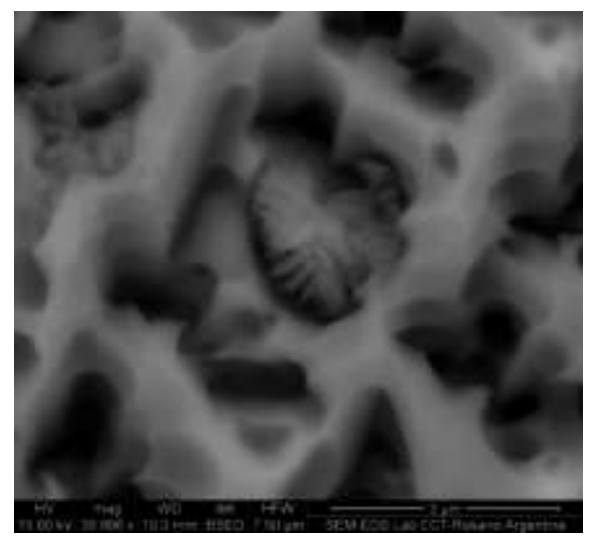

Fig-14: Detail of the dendrites of combeite observed at high magnification in sample $B$

The correlation of all the results allows to identify the mechanisms of gases emission in the samples A and B. Particularly, fluorine gases emission in sample A occur during the melting behaviour. $\mathrm{CaF}_{2}$ content in the mould powder controls the melting behaviour. At $\mathrm{T}_{1 \mathrm{~L}}=750^{\circ} \mathrm{C}$ the first liquid phase with fluorine content in the chemical composition is formed and then at $\mathrm{T} \sim 950^{\circ} \mathrm{C}$ a second liquid phase with $\mathrm{F}$ is also generated. As the temperature increase, fluorine present in the liquid phases start to react and form $\mathrm{NaF}, \mathrm{KF}$ and (NaF) 2 gases. At temperatures $\mathrm{T}=1200^{\circ} \mathrm{C}$ all the gases present similar fugacity values. However, at higher temperatures $\mathrm{NaF}$ fugacity present a drastically increase respect the values of the other gases. This behaviour associated with the viscosity and surface tension evolution with temperature, justify the important $\mathrm{NaF}$ emission during all the continuous casting operation conditions as it was predicted by the thermodynamic simulation (see, Figure-7). The lower fugacity values of the other gases $\left(\mathrm{KF}\right.$ and $(\mathrm{NaF})_{2}$ promote a quite low emission of them. This results allows to consider that when the mould powder $\mathrm{A}$ is applied in the continuous casting gases are permanent emitted to the environment from $\mathrm{T}=1200^{\circ} \mathrm{C}$ to $1500^{\circ} \mathrm{C}$. 
M. Valentini \& E. Brandaleze., Sch Acad J Biosci, October, 2020; 8(10): 321-329

In addition, the results also show that not all the fluorine present in the mould powder is emitted because part of it reacts to form solid crystal phases such as cuspidine and villaumite. All the crystalline phases developed in the sample A provides the required heat extraction for medium carbon steels solidification.

On the opposite, sample B present negligible gases emissions corroborated by TG tests. In spite of, sample B generates liquid phases at a similar temperature respect sample $\mathrm{A}\left(\mathrm{T}_{1 \mathrm{~L}}=750^{\circ} \mathrm{C}\right)$, the possible gases generated in this system such as $\mathrm{Na}, \mathrm{NaBO}_{2}$ and $\mathrm{LiBO}_{2}$ could be emitted at $\mathrm{T} \geq 1350^{\circ} \mathrm{C}$. In this case, the main gas is $\mathrm{Na}$ however it fugacity present a drastically decrease with temperature for this reason the emission tendency also decreases con temperature. On this base it is possible to think that sample B is less harmful to the environment. The $\mathrm{Na}$ gas fugacity decrease, allows to think that this element present a tendency to react and constitute the solid phases of the sample B, identified by XRD and the structural study.

\section{CONCLUSIONS}

The comparative study between the two mould powders $\mathrm{A}$ and $\mathrm{B}$ (with and without $\mathrm{CaF}_{2}$, respectively) including physical properties determination (viscosity $(\eta)$ and surface tension $(\gamma)$ ), the thermal behavior obtained by DTA TG tests and the information obtained through thermodynamic simulation at operation conditions, confirms that sample A generates fluorine gases emissions of $\mathrm{NaF}, \mathrm{KF}$ and $(\mathrm{NaF})_{2}$ from $\mathrm{T} \geq 1250^{\circ} \mathrm{C}$ to $\mathrm{T} \sim 1500^{\circ} \mathrm{C}$. On the opposite, the sample $\mathrm{B}$ develope negligible gases emissions (at $\mathrm{T} \cong 1350^{\circ} \mathrm{C}$ ) and for this reason represents one alternative material less harmful to the environment. The opinion is justified by the fugacity behaviour of $\mathrm{Na}$ gas that drastically decrease with temperature.

The similarities of the physical properties (viscosity and surface tension) and crystallization tendency between both samples allows to think that sample B (lesser harmful for the environment) constitutes a good alternative for processing of medium carbon steels in the continuous casting. It was possible to evaluate that the crystalline phases developed at $1300^{\circ} \mathrm{C}$ in both materials present similar proportions. This result allows to predict that the use of mould flux B could provide a favorable heat extraction in the mould.

The integration of all the results allows to identify the gases mechanisms of generation and emission in both samples. It was possible to determined that $\mathrm{NaF}$ and $\mathrm{KF}$ are the main gas formed in the sample $\mathrm{A}$, as result of fluorine reaction into de liquid phase at $\mathrm{T} \geq 1200^{\circ} \mathrm{C}$. The drastic increase of the $\mathrm{NaF}$ fugacity promotes the emission up to $1500^{\circ} \mathrm{C}$. In the sample $\mathrm{B}$, the $\mathrm{Na}$ gas generated is negligible and do not have favorable conditions be emitted. Probably, $\mathrm{Na}$ reacts with into the liquid phases and finally constitute combeite that is the main crystalline phase identified in the system.

\section{REFERENCES}

1. Fischer YR, de Melo I, Silva LCS, Wanderley VA. Cleaner Production in a Steel Industry, Modern Environmental Science and Engineering, 2015;1(6):341-347.

2. Habashi F. Clean Technology in the Metallurgical Industry, Chemistry for Sustainable Development, 2004; 12:93-98.

3. Zhou L, Wang W, Wei J, Zhou K. Melting and Heat Transfer Behavior of Fluorine-Free Mold Fluxes for Casting Medium Carbon Steels, ISIJ International, , 2015; 55(4):821-829.

4. Brandaleze E, Benavidez E, Santini L. Crystallization study on synthetic fluorine free slags, Acta Microscopica, 2013; 22(1):42-48.

5. Valentini M, Brandaleze E. Use of Borom and Lithium Oxides as a Replacement of Fluoride Compounds in Mold Powders, Scholars Academic Journal of Biosciences (SAJB), 2015; 3(3): 301-308.

6. Wen G, Sridhar S, Tang P, Qi X, Liu Y. Development of Fluoride-free Mold Powders for Peritectic Steel Slab Casting, ISIJ International. 2007; 47:1117-1125.

7. Li G, Wang H, Dai Q, Zhao Y, Li J. Physical Properties and Regulating Mechanism of Fluoride-Free and Harmless $\mathrm{B}_{2} \mathrm{O}_{3}$-Containing Mould Flux, Journal of Iron and Steel Research, International, 2007; 14(1):25-28.

8. Yu X, Wen G, Tang P, Yang B. Characteristics of Heat Flux Through Slag Film of Mold Slag Used for High Al-TRIP Steel Casting, Journal of Iron and Steel Research International. 2010;17: 11-16.

9. Bale CW, Chartrand P, Decterov SA, Eriksson G, Hack K, Ben Mahfoud R, Melançon J, Pelton AD, Petersen S. FactSage Thermochemical Software and Databases, Cal Phad J, 2002;26:189-228.

10. Van Ende M, Jung IH. Development of a thermodynamic database for mold flux and application to the continuous casting process, ISIJ International, 2014;54(8):489-495.

11. Bale CW, Bélisle E, Chartrand P, Decterov DA, Eriksson G, Hack K, Jung IH, Kang YB, Melançon J, Pelton AD, Robelin C, Petersen S. Fact Sage Thermochemical Software and Databases-Recent Developments, Calphad, 2009; 33(2):135-143.

12. Benavidez E, Santini L, Martín A, Di Gresia G, Brandaleze E. Mould fluxes in the steel continuous casting process, Science and Technology of Casting Process, Ch.7, InTech - Open Access Company, 2012.

13. Sheng Y, Mujun L, Peng L, Dengfu Ch, Huamei D, Jie Y. Experimental simulation on the high-temperature friction property of slag in slab continuous casting mold, Journal of Materials Research and Technology, 2020; 9:6453-6463. 
14. Larson D, Suzuki T, Sinha AK, Borges E. Performance of Three to Five Poise Mold Powders with an Exothermic Addition, AISTech 2012 Proceedings, 2012; 1269-1278.

15. Reis BH, Bielefeldt WV, Faria Vilela AC. Absorption of non-metallic inclusions by steelmaking slags - a review, Journal of Materials Research and Technology, 2014; 3:179-185.
16. Nakamoto $\mathrm{M}$, Tanaka T, Holappa $\mathrm{L}$ and Hämäläinen M. Surface Tension Evaluation of Molten Silicates Containing Surface-active Components $\left(\mathrm{B}_{2} \mathrm{O}_{3}, \mathrm{CaF}_{2}\right.$ or $\left.\mathrm{Na}_{2} \mathrm{O}\right)$, ISIJ International, 2007; 47(12):211-216.

17. Persson M, Seetharaman Jr S, Seetharaman S. Kinetic Studies of fluoride evaporation from slags, ISIJ International, 2007; 47(12):1711-1717. 